\title{
Fibroblast growth factor 2 inhibits the expression of stromal cell-derived factor $1 \alpha$ in periodontal ligament cells derived from human permanent teeth in vitro
}

\author{
TAKEYOSHI ASAKAWA ${ }^{1}$, NAOYUKI CHOSA ${ }^{2}$, YOSHITAKA YOSHIMURA ${ }^{3}$, ASAMI ASAKAWA ${ }^{1}$, \\ MITSURO TANAKA $^{1}$, AKIRA ISHISAKI ${ }^{2}$, MASATO MITOME ${ }^{4,5}$ and TOMOKAZU HASEGAWA ${ }^{1,5}$ \\ Departments of ${ }^{1}$ Pediatric Dentistry and ${ }^{2}$ Oral Biochemistry, School of Dentistry, Iwate Medical University, \\ Morioka 020-8505; ${ }^{3}$ Department of Molecular Cell Pharmacology, Division of Oral Pathological Science, Hokkaido \\ University Graduate School of Dental Medicine, Kita-ku, Sapporo 060-8586; ${ }^{4}$ Department of Pediatric Dentistry, \\ Institute of Health Biosciences, University of Tokushima Graduate School, Tokushima 770-8504; \\ ${ }^{5}$ Department of Pediatric Dentistry, Tokushima University Hospital, Tokushima 770-8504, Japan
}

Received October 19, 2011; Accepted November 29, 2011

DOI: $10.3892 /$ ijmm.2011.869

\begin{abstract}
Although cells derived from periodontal ligament (PDL) tissue are reported to have stem cell-like activity and are speculated to play a crucial role for tissue healing and regeneration after injury or orthodontic treatment, mechanisms regulating their recruitment and activation remain unknown. Recently, stromal cell-derived factor $1 \alpha(\mathrm{SDF}-1 \alpha)$ has been reported to be important for stem cell homing and recruitment to injured sites. The aim of this study was to evaluate whether fibroblast growth factor 2 (FGF-2) affects the expression of SDF-1 $\alpha$ in PDL cells derived from human permanent teeth in vitro. Using real-time PCR, the expression of SDF- $1 \alpha$ mRNA in PDL cells was inhibited by treatment with $10 \mathrm{ng} / \mathrm{ml}$ FGF-2. When PDL cells were treated with SU5402 (an inhibitor of FGF receptor 1) in combination with FGF-2, the FGF-2-reduced expression of SDF-1 $\alpha$ was inhibited. In the presence of the JNK inhibitor SP600125, SDF-1 $\alpha$ mRNA in PDL cells was not suppressed by the FGF-2 treatment. Western blot analysis also showed that SDF-1 $\alpha$ production was suppressed by treatment with FGF-2, but it recovered with treatment by FGF-2 + SU5402. These findings suggest that SDF- $1 \alpha$ from PDL cells plays an important role in the regeneration and homeostasis of periodontal tissues via the recruitment of stem cells.
\end{abstract}

\section{Introduction}

The periodontal ligament (PDL) is located between the tooth root and alveolar bone (1). Most PDL cells are fibroblasts

\footnotetext{
Correspondence to: Dr Tomokazu Hasegawa, Department of Pediatric Dentistry, Tokushima University Hospital, 3-18-15 Kuramoto, Tokushima 770-8504, Japan

E-mail: hasegawa@dent.tokushima-u.ac.jp
}

Key words: stromal cell-derived factor $1 \alpha$, fibroblast growth factor 2, periodontal ligament cells, permanent tooth with relatively high alkaline phosphatase (ALP) activity $(2,3)$. Fibroblasts derived from the PDL have the ability to form bonelike tissues in vitro, similar to osteoblasts $(2,3)$, and thus, PDL cells function similarly to osteoblasts in hard tissue formation. Recently, several studies have demonstrated that PDL cells also differentiate into cementoblastic and adipogenic cells in vitro (4). Therefore, the PDL probably contains pluripotent progenitor cells or putative stem cells. However, the mechanism of PDL cell migration is poorly understood.

Stromal cell-derived factor $1 \alpha$ (SDF-1 $\alpha$, also known as CXCL12) is an $\alpha$-chemokine that strongly chemoattracts mesenchymal stem cells (MSCs) and endothelial progenitor cells (EPCs) via interaction with its unique receptor CXCR4 (5). In adults, tissue repair and regeneration after injury are thought to involve the selective recruitment of circulating or resident stem cell populations. The importance of SDF-1 $\alpha$ in stem and progenitor cell recruitment has been established by showing that its expression in injured tissue correlates with the recruitment of adult stem cells and tissue regeneration (5-8). Therefore, SDF-1 $\alpha$, as a type of stem cell-development factor and chemokine, plays an important role in coordinating tissue injury and repair.

For regenerative therapy, biologically active soluble factors such as cytokines and growth factors are being evaluated for clinical use in the regeneration of periodontal tissue damaged or lost as a result of periodontitis. Of these factors, fibroblast growth factor 2 (FGF-2) is a multifunctional growth factor that has a variety of effects, including the induction of proliferation and differentiation in a wide range of mesodermal and neuro-ectodermal cells (9). Therefore, we investigated whether FGF-2 could regulate the expression of SDF-1 $\alpha$ in cultured PDL cells in vitro.

\section{Materials and methods}

Reagents. FGF-2 was obtained from R\&D Systems (Minneapolis, MN, USA). Anti-SDF-1 $\alpha$ polyclonal antibody for the western blot analysis was obtained from Abcam (ab9797, Cambridge, 
UK). SU5402 (10 $\mu \mathrm{M})$, SP600125 (10 $\mu \mathrm{M})$, U0126 (10 $\mu \mathrm{M})$, SB203580 $(10 \mu \mathrm{M})$ and LY294002 $(10 \mu \mathrm{M})$ were purchased from EMD Chemicals, Inc. (Calbiochem; Gibbstown, NJ, USA).

Cell culture. PDL tissues were obtained from the middle third of the root surfaces of healthy human permanent teeth (3 donors, aged 7-8 years), as previously described $(10,11)$. Informed consent was obtained from the donors' parents before tooth extraction, which was carried out in our hospital during the course of orthodontic treatment. This study protocol was approved by the Ethics Committee of the Iwate Medical University, School of Dentistry (no. 01101).

The PDL tissues were cut into pieces using a surgical blade and were digested with collagenase $(2 \mathrm{mg} / \mathrm{ml})$ at $37^{\circ} \mathrm{C}$ for $30 \mathrm{~min}$. The tissues were then washed with Dulbecco's phosphate-buffered saline (PBS), placed on culture dishes, and maintained in $\alpha$-modified minimum essential medium ( $\alpha$-MEM; Life Technologies Corp., Carlsbad, CA, USA) supplemented with $10 \%$ fetal bovine serum (FBS; Life Technologies Corp.). Fibroblastic cells that grew out from the PDL tissues were used as PDL cells. When the cells reached confluence, they were detached with $0.2 \%$ trypsin and $0.02 \%$ EDTA-4Na in PBS and subcultured at a 1:4 split ratio. All of the experiments were performed using fourth passage cells cultured in $\alpha$-MEM supplemented with 10\% FBS in the absence or presence of $10 \mathrm{ng} / \mathrm{ml} \mathrm{FGF}-2$ for between 24 and $48 \mathrm{~h}$. All of the cultures were maintained at $37^{\circ} \mathrm{C}$ in a humidified atmosphere of $5 \% \mathrm{CO}_{2}$ in air.

Isolation of total-RNA. Total-RNA was extracted from the cultured PDL cells using ISOGEN (Nippon Gene, Tokyo, Japan) as described previously $(10,11)$. The pellet of total-RNA was washed briefly with $75 \%$ ethanol, resuspended in $30 \mu 1$ of diethylpyrocarbonate (DEPC)-treated water, and stored at $-80^{\circ} \mathrm{C}$. The concentration of total-RNA was determined spectrophotometrically by measuring the optical density at $260 \mathrm{~nm}$.

Quantitative real-time reverse transcription-polymerase chain reaction. One microgram of the RNA sample was reverse-transcribed to first-strand cDNA using a PrimeScript RT reagent kit (Takara Bio, Inc., Shiga, Japan) according to the manufacturer's protocol. A Thermal Cycler Dice real-time
Table I. Primers used in the quantitative real-time PCR reverse transcription-polymerase chain reaction (real-time PCR).

\begin{tabular}{ll}
\hline Gene name & \multicolumn{1}{c}{ Origonucleotide sequence (5'-3') } \\
\hline SDF-1 & F: GAGCCAACGTCAAGCATCTCAA \\
GAPDH & R: TTTAGCTTCGGGTCAATGCACA \\
& F: GCACCGTCAAGGCTGAGAAC \\
& R: TGGTGAAGACGCCAGTGGA
\end{tabular}

SDF-1, stromal cell-derived factor $1 \alpha$; GAPDH, glyceraldehyde 3-phosphate dehydrogenase.

system (Takara Bio, Inc.) was used for the two-step reverse transcription-polymerase chain reaction. The cDNA was amplified with SYBR Premix ExTaq (Takara Bio, Inc.) and specific oligonucleotide primers for target sequences encoding parts of SDF- $1 \alpha$. The primers (Table I) were designed based on the cDNA sequences of human mRNA for SDF- $1 \alpha$ and glyceraldehyde-3-phosphate dehydrogenase (GAPDH). Amplification conditions consisted of $10 \mathrm{sec}$ at $95^{\circ} \mathrm{C}$, followed by 40 cycles at $95^{\circ} \mathrm{C}$ for $5 \mathrm{sec}$ and $60^{\circ} \mathrm{C}$ for $30 \mathrm{sec}$, with a final $15 \mathrm{sec}$ at $95^{\circ} \mathrm{C}$ and $30 \mathrm{sec}$ at $60^{\circ} \mathrm{C}$ in the Thermal Cycler Dice real-time system $(12,13)$.

Western blot analysis of SDF-1 $\alpha$ expression from PDL cells. After treatment with FGF-2 for 7 days, the conditioned media from PDL cell culture were collected for SDF- $1 \alpha$ analysis. Subsequently, $20 \mu \mathrm{l}$ of conditioned media were dissolved in SDS buffer without dithiothreitol, incubated at $95^{\circ} \mathrm{C}$ for $5 \mathrm{~min}$, resolved electrophoretically on $10 \%$ SDS-polyacrylamide gels and transferred to a polyvinylidene difluoride membrane (Millipore Corp., Bedford, MA, USA). After being blocked with 5\% skim milk in Tris-buffered saline containing $0.1 \%$ Tween-20 (TBST), the membrane was incubated with mouse anti-human SDF-1 $\alpha$ antibodies and subsequently with antimouse secondary antibodies (Life Technologies Corp.). Specific protein bands on the membrane were detected using an enhanced AP conjugate substrate kit (Bio-Rad Laboratories, Inc., Hercules, CA, USA) as previously described (10-13).
CONTROL

$24 h$

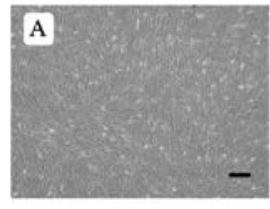

$48 \mathrm{~h}$

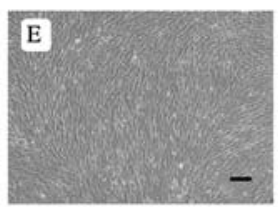

FGF-2
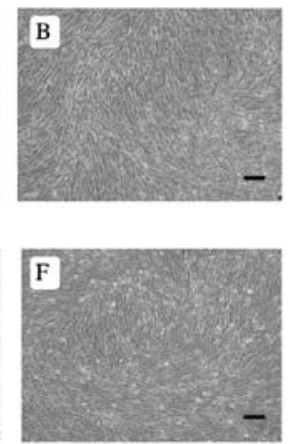

SU5402
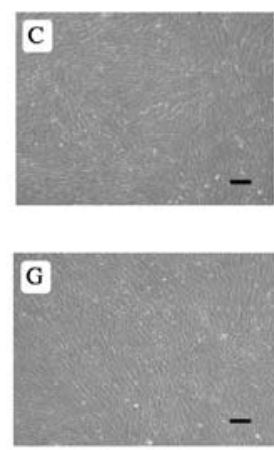
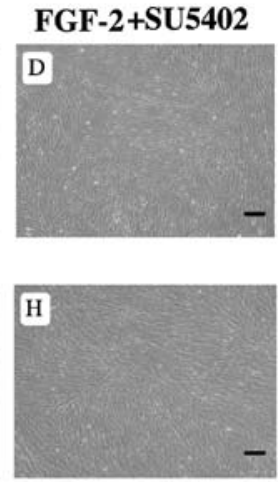

Figure 1. Effect of FGF-2 on the morphology of PDL cells derived from human permanent teeth. PDL cells cultured in control medium for $24 \mathrm{~h}$ (A) and $48 \mathrm{~h}$ (E) showed confluence. PDL cells cultured in the presence of SU5402 (C and G) showed no differences from PDL cells cultured in control medium. When PDL cells were cultured in the presence of FGF-2 for $24 \mathrm{~h}$ (B) and $48 \mathrm{~h}(\mathrm{~F})$, the PDL cell morphology was altered into long, thin, spindle-shaped fibroblastic cells PDL cells cultured in both FGF-2 and SU5402 (FGF-2 + SU5402) were similar to those cultured in control medium (D and H). Bar, $100 \mu \mathrm{m}$. 


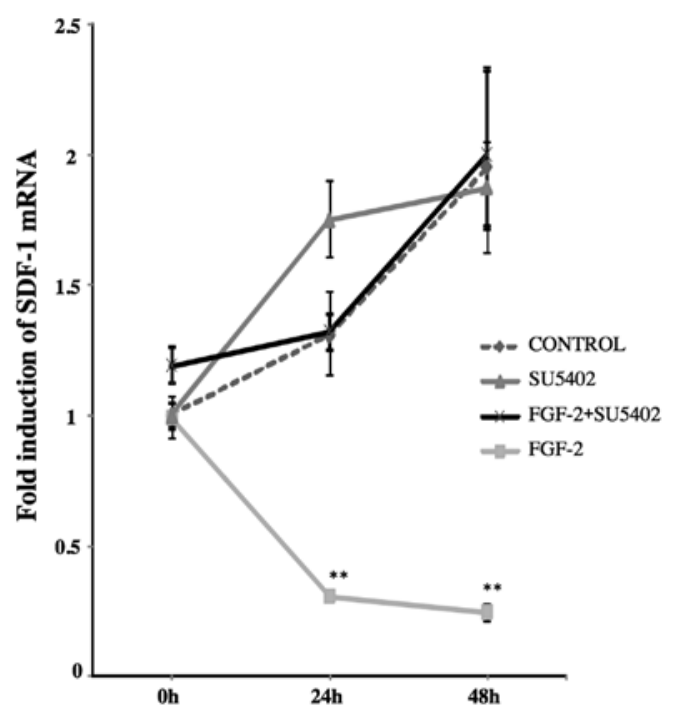

Figure 2. Real-time PCR analysis for SDF-1 $\alpha$ mRNA expression. The expression of SDF-1 $\alpha$ mRNA in PDL cells increased at 24 and $48 \mathrm{~h}$ when cultured in the control media and in the presence of SU5402 and FGF-2 + SU5402. Expression of SDF-1 $\alpha$ mRNA in PDL cells treated with FGF-2 was significantly reduced at 24 and $48 \mathrm{~h}$. Values are expressed as a ratio with respect to SDF-1 $\alpha$ expression at $0 \mathrm{~h} .{ }^{* *} \mathrm{P}<0.01$.

A

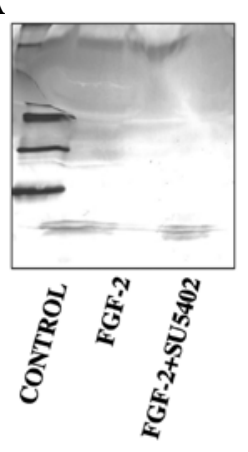

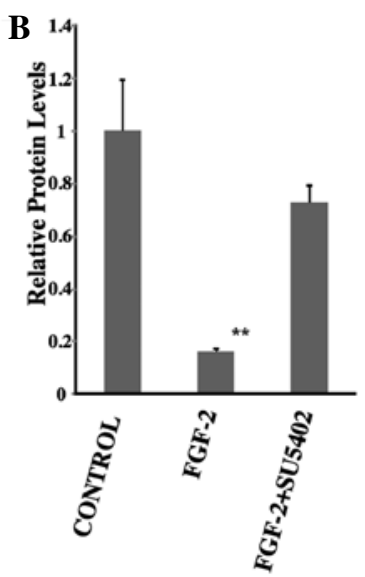

Figure 3. Western blot analysis of SDF-1 $\alpha$ expression in PDL cells. (A) SDF-1 $\alpha$ was detected in conditioned media when PDL cells were cultured in control media and in FGF-2 + SU5402 media. SDF-1 $\alpha$ expression was reduced in the presence of FGF-2. (B) When measured with densitometry, SDF-1 $\alpha$ expression in FGF-2-treated PDL cells was significantly decreased compared to both the control and FGF-2 + SU5402 conditions. Values are expressed as a ratio with respect to SDF-1 $\alpha$ expression in control media. ${ }^{* *} \mathrm{P}<0.01$.

Statistical analysis. The results are expressed as means \pm SEM. Statistical significance was determined using one-way analysis of variance with Bonferroni post hoc comparisons between pairs of groups. The threshold for statistical significance was set $a$ priori at $\mathrm{P}<0.01$.

\section{Results}

FGF-2 induces morphological changes. Morphological changes in PDL cells were induced by treatment with FGF-2 for 24-48 h. After culturing for 24-48 h, PDL cells reached confluence in control media (Fig. 1A and E) and in the presence of FGF-2 (Fig. 1B and F). When treated with FGF-2,

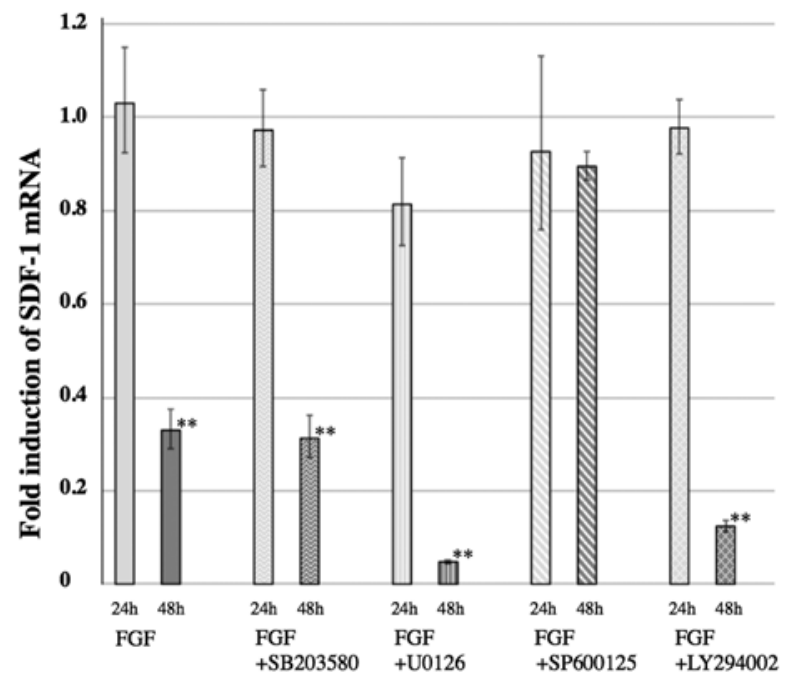

Figure 4. The effect of MAP kinase and Akt pathway inhibitors on SDF-1 $\alpha$ expression. When PDL cells were cultured in the presence of various key signal pathway inhibitors $(10 \mu \mathrm{mol} / 1$ each of U0126, SB203580, SP600125 and LY294002) for $48 \mathrm{~h}, \mathrm{SDF}-1 \alpha$ expression was examined. The reduction of SDF-1 $\alpha$ expression by FGF-2 treatment was inhibited by culturing PDL cells in the presence of FGF-2 + SP600125. Values are expressed as a ratio with respect to SDF-1 $\alpha$ expression in control media. ${ }^{* *} \mathrm{P}<0.01$.

PDL cells altered their morphology into long, thin, spindleshaped fibroblasts (Fig. 1B and F). There were no differences in the appearance of PDL cells between control and SU5402 treatment (Fig. 1A, C, E and G), or between control and FGF-2 + SU5402 (Fig. 1A, C, D and H).

FGF-2 suppresses SDF-1 $\alpha$ mRNA expression. Expression of SDF- $1 \alpha$ mRNA was suppressed in PDL cells cultured in the presence of FGF-2 for 24 and $48 \mathrm{~h}$. When PDL cells were cultured in the presence of FGF-2 for 24 and $48 \mathrm{~h}$, SDF- $1 \alpha$ mRNA expression was significantly decreased compared to the $0 \mathrm{~h}$ level $(0 \mathrm{~h}$, $1 ; 24 \mathrm{~h}, 0.3 ; 48 \mathrm{~h}, 0.2 ; \mathrm{P}<0.01)$. However, after treating with SU5402 alone and FGF-2 + SU5402, SDF-1 $\alpha$ expression was slightly increased (Fig. 2).

$F G F-2$ decreased SDF-1 $\alpha$ expression. SDF-1 $\alpha$ expression decreased in PDL cells cultured in the presence of FGF-2. After treatment with FGF-2 for 7 days, the production of SDF-1 $\alpha$ was noticeably decreased in PDL cells compared to the control (control, 1; FGF-2, 0.16; P<0.01) (Fig. 3). However, in the presence of FGF-2 + SU5402, SDF-1 $\alpha$ expression was slightly decreased compared with control, although this was not statistically significant (control, 1; FGF-2 + SU5402, 0.72).

SP600125 inhibites the FGF-2-mediated decrease in SDF-1a expression. The decreased expression of SDF- $1 \alpha$ in PDL cells, mediated by FGF-2, was inhibited by SP600125, an inhibitor of JNK. Only the treatment of FGF-2 + SP600125 inhibited the decreased expression of SDF-1 $\alpha$ observed when PDL cells were cultured with FGF-2 alone (Fig. 4). Other MAP kinase inhibitors, U0126 (an MEK1/2 inhibitor) and SB203580 (a p38 kinase inhibitor), had no effect on the decreased expression of SDF-1 $\alpha$. LY294002, a phosphatidylinositol-3 kinase (PI3K) inhibitor, also had no effect on the decreased expression of SDF-1 $\alpha$ (Fig. 4). 


\section{Discussion}

This study demonstrated that SDF-1 $\alpha$ mRNA was inhibited in cultured PDL cells by treatment with FGF-2. Decreased expression of SDF-1 $\alpha$ was also demonstrated in conditioned media from PDL cells cultured with FGF-2. This is the first report of altered SDF-1 $\alpha$ expression regulated by FGF- 2 treatment in PDL cells derived from human permanent teeth.

PDL tissue regeneration and homeostasis in response to pathological and environmental changes, such as injury and orthodontic treatment, are thought to depend on recruitment of circulating or resident stem cells. SDF-1 $\alpha$ plays an important role in tissue healing by recruiting endothelial progenitor cells and MSCs from the bone marrow through its receptor, CXCR4 (5-8). However, it remains unclear whether the recruitment of stem and progenitor cells can be regulated in PDL tissue.

In this study, PDL cells derived from human permanent teeth were used to investigate the effects of FGF-2 on the expression of SDF-1 $\alpha$, using real-time PCR. Previous studies have shown that PDL cells not stimulated with FGF-2 basally express SDF-1 $\alpha$ $(14,15)$. The results of the current study support those findings; PDL cells expressed SDF-1 $\alpha$ in the absence of FGF-2 (Fig. 2). Surprisingly, PDL cells significantly decreased the expression of SDF-1 $\alpha$ when cultured in the presence of FGF-2 (Fig. 2). In addition, this study demonstrated that SDF-1 $\alpha$ expression was regulated by FGF-2 via the fibroblast growth factor receptor (FGFR). Results showed levels of SDF-1 $\alpha$ expression similar to those of the control when cultured in media with combined FGF-2 and an FGF receptor antagonist, SU5402. No statistical differences in SDF-1 $\alpha$ expression were found between untreated cells and cells treated with SU5402 alone.

Western blot analysis showed that SDF-1 $\alpha$ protein production in conditioned media was significantly decreased by treatment with FGF-2 compared to the control group. In the presence of FGF-2 + SU5402, SDF-1 $\alpha$ expression recovered almost to control levels (Fig. 3). Similarly to the real-time PCR results, this analysis suggests that FGF-2 inhibits SDF-1 $\alpha$ protein expression in PDL cells via the FGFR.

A phosphatidylinositol-3 kinase (PI3K) inhibitor, LY2940002, blocks PI3K and results in the inhibition of Akt pathway activity. It has previously been shown that FGF-2-induced Akt phosphorylation depends upon PI3K in MSCs (16). In the presence of FGF-2 + LY2940002, FGF-2reduced expression of SDF-1 $\alpha$ was not inhibited in PDL cell culture. Therefore, the current results indicate that the PI3K/ Akt pathway is not related to FGF-2-reduced expression of SDF- $1 \alpha$ in PDL cells.

Furthermore, the specific MEK inhibitor U0126 or the p38 MAP kinase inhibitor SB202190 in combination with FGF-2 had no effect on FGF-2-induced SDF-1 $\alpha$ inhibition (Fig. 4). However, the JNK inhibitor SP600125 in combination with FGF-2 inhibited FGF-2-reduced expression of SDF-1 $\alpha$ (Fig. 4). These results indicate that the JNK pathway plays an important role in FGF-2-mediated effects in PDL cells.

FGF-2 has been described as a multipotent cytokine that regulates cell proliferation as well as differentiation, matrix composition, and migration in a number of cell types (9). It has also been shown that FGF-2 itself as well as SDF-1 $\alpha$ could control MSC migration (5-8,17). SDF-1 $\alpha$ expression levels in clinically inflamed dental pulp tissues were higher than those in healthy dental pulp (18). Moreover, human gingival fibroblasts constitutively expressed SDF-1 $\alpha$ (19). This expression was enhanced by stimulation with tumor necrosis factor- $\alpha$ (TNF- $\alpha$ ) and transforming growth factor- $\beta$ (TGF- $\beta$ ) (19). Together with these results, it can be concluded that PDL cells in an environment where FGF-2 is abundant may decrease SDF- $1 \alpha$ expression because FGF- 2 is capable of inducing the migration of MSCs.

This is the first study to demonstrate that the treatment of PDL cells derived from human permanent teeth with FGF-2 in vitro regulates SDF-1 $\alpha$ expression. These findings can aid in understanding of mechanisms of PDL tissue regeneration by suggesting that with effective regulation of SDF-1 $\alpha$ expression, MSC migration can be controlled.

\section{Acknowledgements}

This study was supported in part by Grants-in-Aid for Scientific Research (nos. 18592026, 23592896 to A.I., no. 19791370 to N.C., no. 21390548 to M.M., and nos. 18592239 and 22592296 to T.H.) and Grant-in-Aid for Challenging Exploratory Research (no. 23659965 to M.M.) from the Ministry of Education, Culture, Sports, Science and Technology of Japan; the Open Research Project and High-Tech Research Project from the Ministry of Education, Culture, Sports, Science and Technology of Japan; and the Medical Innovation by Advanced Science and Technology (MIAST) a project; Grant-in-Aid for Strategic Medical Science Research Center from the Ministry of Education, Culture, Sports, Science and Technology of Japan, 2010-2014; the Akiyama Foundation (to T.H., 2005); and a grant from the Keiryokai Research Foundation (no. 100 to N.C., 2008; no. 103 to A.I. and no. 106 to T.H., 2009).

\section{References}

1. Freeman E: Periodontium. In: Oral Histology: Development, Structure and Function. Ten Cate AR (ed). Mosby, St. Louis, pp276-312, 1994.

2. Groeneveld MC, Everts V and Beertsen W: Alkaline phosphatase activity in the periodontal ligament and gingiva of the rat molar: its relation to cementum formation. J Dent Res 74: 1374-1381, 1995.

3. Beertsen W and van den Bos T: Alkaline phosphatase induces the mineralization of sheets of collagen implanted subcutaneously in the rat. J Clin Invest 89: 1974-1980, 1992.

4. Seo BM, Miura M, Gronthos S, Bartold PM, Batouli S, Brahim J, Young M, Robey PG, Wang CY and Shi S: Investigation of multipotent postnatal stem cells from human periodontal ligament. Lancet 364: 149-155, 2004.

5. Wang J, Loberg R and Taichman RS: The pivotal role of CXCL12 (SDF-1)/CXCR4 axis in bone metastasis. Cancer Metastasis Rev 25: 573-587, 2006.

6. Zernecke A, Schober A, Bot I, von Hundelshausen P, Liehn EA, Möpps B, Mericskay M, Gierschik P, Biessen EA and Weber C: SDF-1alpha/CXCR4 axis is instrumental in neointimal hyperplasia and recruitment of smooth muscle progenitor cells. Circ Res 96: 784-791, 2005.

7. Kucia M, Ratajczak J, Reca R, Janowska-Wieczorek A and Ratajczak MZ: Tissue-specific muscle, neural and liver stem/ progenitor cells reside in the bone marrow, respond to an SDF-1 gradient and are mobilized into peripheral blood during stress and tissue injury. Blood Cells Mol Dis 32: 52-57, 2004.

8. Ratajczak MZ,Kucia M, Reca R, Majka M,Janowska-Wieczorek A and Ratajczak J: Stem cell plasticity revisited: CXCR4-positive cells expressing mRNA for early muscle, liver and neural cells 'hide out' in the bone marrow. Leukemia 18: 29-40, 2004.

9. Murakami S: Periodontal tissue regeneration by signaling molecule(s): what role does basic fibroblast growth factor (FGF-2) have in periodontal therapy? Periodontology 56: 188-208, 2011. 
10. Hasegawa T, Yoshimura Y, Kikuiri T, Yawaka Y, Takeyama S, Matsumoto A, Oguchi $\mathrm{H}$ and Shirakawa T: Expression of receptor activator of NF-kappa B ligand and osteoprotegerin in culture of human periodontal ligament cells. J Periodont Res 37: 405-411, 2002

11. Hasegawa T, Kikuiri T, Takeyama S, Yoshimura Y, Mitome M, Oguchi $\mathrm{H}$ and Shirakawa T: Human periodontal ligament cells derived from deciduous teeth induce osteoclastogenesis in vitro. Tissue Cell 34: 44-51, 2002.

12. Hasegawa T, Chosa N, Asakawa T, Yoshimura Y, Asakawa A, Ishisaki A and Tanaka M: Effect of fibroblast growth factor-2 on periodontal ligament cells derived from human deciduous teeth in vitro. Exp Ther Med 1: 337-341, 2010.

13. Hasegawa T, Chosa N, Asakawa T, Yoshimura Y, Asakawa A, Ishisaki A and Tanaka M: Effect of fibroblast growth factor-2 on dental pulp cells derived from human deciduous teeth in vitro. Exp Ther Med 1: 477-480, 2010.

14. Trubiani O, Isgro A, Zini N, Antonucci I, Aiuti F, Di Primio R, Nanci A, Caputi S and Paganelli R: Functional interleukin-7/ interleukin-7Ralpha, and SDF-1alpha/CXCR4 are expressed by human periodontal ligament derived mesenchymal stem cells. J Cell Physiol 214: 706-713, 2008.
15. Nagatomo K, Komaki M, Sekiya I, Sakaguchi Y, Noguchi K, Oda S, Muneta T and Ishikawa I: Stem cell properties of human periodontal ligament cells. J Periodontal Res 41: 303-310, 2006

16. Choi SC, Kim SJ, Choi JH, Park CY, Shim WJ and Lim DS: Fibroblast growth factor- 2 and -4 promote the proliferation of bone marrow mesenchymal stem cells by the activation of the PI3K-Akt and ERK1/2 signaling pathways. Stem Cells Dev 17: 725-736, 2008.

17. Schmidt A, Ladage D, Schinköthe T, Klausmann U, Ulrichs C, Klinz FJ, Brixius K, Arnhold S, Desai B, Mehlhorn U, et al: Basic fibroblast growth factor controls migration in human mesenchymal stem cells. Stem Cells 24: 1750-1758, 2006.

18. Jiang L, Zhu YQ, Du R, Gu YX, Xia L, Qin F and Ritchie HH: The expression and role of stromal cell-derived factor-1alphaCXCR4 axis in human dental pulp. J Endod 34: 939-944, 2008.

19. Hosokawa Y, Hosokawa I, Ozaki K, Nakae H, Murakami K, Miyake Y and Matsuo T: CXCL12 and CXCR4 expression by human gingival fibroblasts in periodontal disease. Clin Exp Immunol 141: 467-474, 2005. 